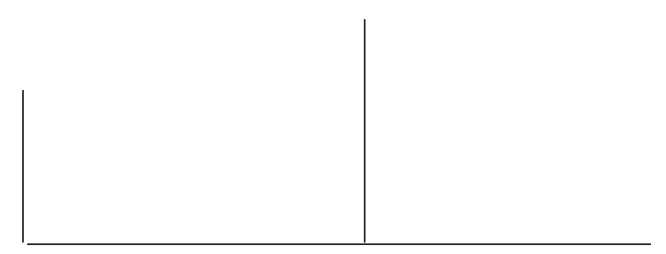

Rev. Latinoam. Psicopat. Fund., IV, 4, 30-42

\title{
Hamlet e a melancolia
}

\author{
Elisa Maria de Ulhôa Cintra
}

O texto apresenta uma análise do primeiro solilóquio de Hamlet, de Shakeaspeare, como ilustração poética do processo mais primitivo de construção de ideais do ponto de vista psicanalítico.

Do lado do ideal de máxima perfeição (Eu Ideal) estão o pai de Hamlet e a situação familiar primordial (Old Hamlet, Gertrude e Hamlet) formando uma tríade narcisista primária.

Do lado contrário (eu abjeto) o texto explora o maior grau de abjeção a que pode chegar um ser humano, neste caso Gertrude, mãe de Hamlet, ao casar-se com Claudius, depois da morte do Velho Hamlet.

A oscilação entre estas posições extremas no eixo dos valores indica a falta de transformação do narcisismo primário e a impossibilidade de construir ideais secundários (ideais do Eu).

Palavras-chave: Hamlet, psicanálise, melancolia, ego ideal 


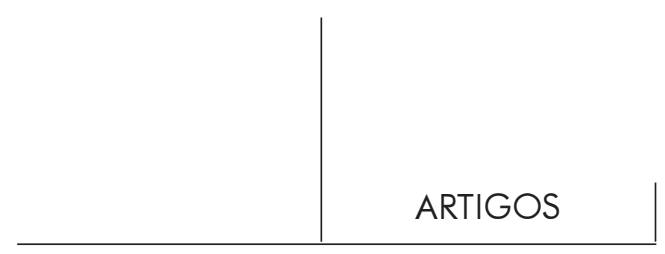

Hamlet ${ }^{1}$ foi citado por Freud dezenas de vezes ao longo de sua obra para exemplificar uma situação edípica particularmente intensa e mal resolvida. Depois disso, foi objeto de diversas leituras, sendo as de Ernest Jones (1954) e Lacan (1989) as mais conhecidas. Interessei-me por estudar, no primeiro monólogo do príncipe, a expressão dilacerante de uma queda abissal: do mais elevado ao mais abjeto ponto de mira dos ideais, do ideal de máxima perfeição, Eu Ideal, a uma condição abjeta da existência, o que talvez nos permita dizer, com a licença do poeta, que não houve suficiente transformação do narcisismo primário e não se constituíram ideais secundários ou ideais do Eu.

Nesse primeiro solilóquio, ${ }^{2}$ Hamlet dirige os mais veementes ataques à sua mãe e ao odiado tio, ao mesmo tempo em que refaz o quadro paradisíaco e hiperidealizado dos pais da primeira infância: a pureza e elevação desta primeira união, a beleza do casal parental destruída pela súbita intrusão de fatores perturbadores como a sexualidade, o incesto e a morte. Hamlet investe contra a "sexualidade incontrolável da mãe", transformando-a em um ser abjeto, muito abaixo de uma prostituta.

1. Há cerca de trinta e sete referências de Freud a Hamlet, quase sempre no contexto de elaboração do Complexo de Édipo. A primeira referência, em uma carta a Fliess (vol. I das Obras completas, p. 307-308) caracteriza Hamlet como "histérico". Entretanto, ao estudar a melancolia, sobretudo o avassalador sentimento de culpa e a depreciação de si e do mundo, Freud descreveu um funcionamento psíquico que pode ser muito bem exemplificado por meio do príncipe dinamarquês.

2. No primeiro solilóquio, bem no início da peça, Hamlet acha-se indignado com o segundo casamento de sua mãe, embora ainda não tenha descoberto que o pai fora assassinado por Claudius. 


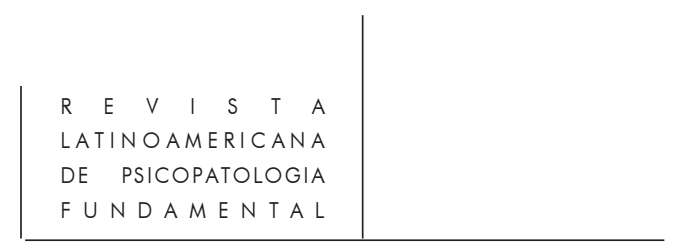

Pela extrema virulência da linguagem é possível ler a magnitude do que foi quebrado, o peso e o trauma de ver rompida a harmonia com os pais, a pura ternura isenta de ódio, inveja, ciúme e rivalidades. Percebe-se em que desmedida proporção a primeira relação idílica com os pais obriga a desprezar este corpo pesado e sexual; desencadeia um movimento insidioso, veloz, de retirar valor do Eu-corpo-atual, tornálo precário, cheio de defeitos, nada, quase nada e quão(!) infinitamente distante da perfeição ideal.

Hamlet realiza algo comparável ao trabalho de destruição do Eu atual que assistimos em todos os pacientes deprimidos (sendo ainda mais dramática na melancolia); a violenta depreciação da mãe, estendida a si próprio, sobretudo em sua dimensão "carnal" é um verdadeiro trabalho melancólico de depreciação da vida e da capacidade de procriação. $\mathrm{O}$ deslizamento da abjeção materna para todos, por meio de uma referência generalizante à carne, culmina no lamento de que "esta carne" possa ter chegado a tal ponto de degradação. Isto é, toda a carne, sujeita à sensualidade torna-se podre e tende a se degenerar cada vez mais; todas as imagens de fecundidade e concepção (ligadas, no texto, à idéia de vir a ter sementes) ficam alinhadas à idéia de apodrecer, tornar-se indecente e aviltante; a capacidade de gerar torna-se degradante, descender é degradar-se.

Em contrapartida, há uma extrema valorização da virgindade e uma idealização

32 da forma de amor pré-genital, que se faz acompanhar de imagens da parte superior do corpo, principalmente da face, da troca apaixonada de olhares, sorrisos e palavras, das carícias que incidem sobre o rosto. É a novela amorosa que se desenrola ao redor da zona erógena da boca, transbordando então para os olhos e a parte superior do corpo, solar, apolínea, elevada. Quando entram em ação as terríveis potências infernais das regiões baixas ocorre uma verdadeira revolução desta primeira ordem, que chamo de narcisista e assexual para diferenciá-la do momento seguinte, quando as forças telúricas e ctônicas entram em jogo.

A linguagem é enloqüente: chamar pelo nome de carne é despersonalizar, tornar todos iguais em sua aviltante carnalidade. Hamlet expressa intenso desejo de voltar toda destrutividade contra a própria carne; em sua exaltação parece não estabelecer diferença entre a abjeção materna, a sua e a dos demais. Neste momento lamenta haver uma lei contra o suicídio (self slaughter), invoca Deus, o Todo Poderoso, o Eterno (Everlasting) para reclamar disto. O termo self slaugther, é muito mais forte do que autodestruição, pois tem a conotação de uma chacina, matança ou destruição de si muito violenta.

A seguir, o texto do primeiro solilóquio, com uma tradução minha, para o propósito desta leitura: 


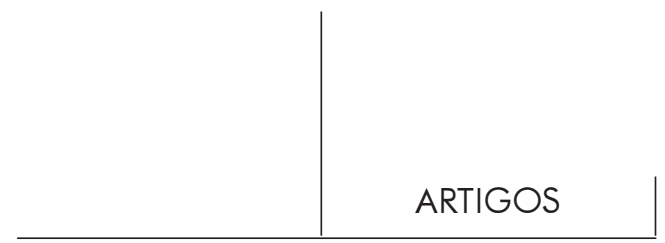

O that this too too sullied ${ }^{3}$

flesh would melt,

Thaw, and resolve itself into a dew, Or that the Everlasting had not fixed

His canon ${ }^{4}$ 'gainst self-slaughter. O God,

God, How weary, stale, flat and unprofitable

Seem to me all the uses of this world! Fie on't, ah, fie, 'tis an unweeded garden

That grows to seed. Things rank and gross in nature

Possess it merely. ${ }^{5}$ That it should come to this:

But two months dead, nay, not so much, not two,

So excellent a king, that was to this Hyperion $^{6}$ to a satyr, so loving to my mother

That he might not beteem ${ }^{7}$ the winds of heaven

Visit her face too roughly. Heaven and earth Must I remember? Why, she would hang on him

As if increase of appetite had grown

By what it fed on; and yet within a month -

Let me not think on'it; frailty, thy name is woman -

A little month, or ere those shoes were old
Oh, e pensar que esta carne tão, tão manchada possa se derreter,

se desmanchar e se dissolver em umidade, Ou se o Todo-poderoso não houvesse fixado sua lei contra a chacina de si. Ó Deus, Deus, Quão cansativos, velhos, superficiais e não proveitosos

Parecem-me todos os objetivos deste mundo.

Vergonha, ó vergonha; (ela) é um jardim de onde não foram retiradas as ervas daninhas que crescem para frutificar. As coisas são indecentes e aviltantes na natureza.

Até possuí-la por inteiro. Que tenha podido chegar a isto

Há dois meses morto, não, não chega a tanto,

Tão excelente rei, era ele para isto Hipérion para um sátiro, tão amoroso para com minha mãe

Que chegava a não permitir que a brisa do paraíso

Tocasse com força em sua face. Céus e terra Devo me lembrar? Como ela se pendurava nele como se aumentasse o apetite a partir daquilo de que se alimentava e ainda assim, no prazo de um mês que eu possa não mais pensar em tudo isto,

Fraqueza, teu nome é mulher!

Um pequeno mês, ou antes que seus sapatos envelhecessem

3. Sullied, manchada. Há uma versão que coloca neste lugar a palavra solid para falar da carne sólida que então derrete, amolece, possível referência ao que acontece com o órgão sexual masculino e também uma metáfora da perda de caráter da mãe de Hamlet.

4. Canon, law, lei.

5. Merely, entirely, inteiramente.

6. Hyperion, the sun god, a model of beauty. $\mathrm{O}$ deus sol, um modelo de beleza.

7. Beteem, allow, permitir. 


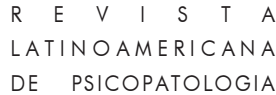

With which she followed my poor father's body

Like Niobe, ${ }^{8}$ all tears, why she, even she -

O God, a beast that wants discourse of reason ${ }^{9}$

Would have mourned longer married with my uncle,

My father's brother, but no more

like my father

Than I to Hercules. Within a month,

Ere yet the salt of most unrighteous tears

Had left the flushing in her gallèd eyes,

She married. O, most wicked speed, to post ${ }^{10}$

With such dexterity to incestuous ${ }^{11}$ sheets!

It is not, nor it cannot come to good. But break my heart, for I must hold com os quais acompanhou o corpo de meu pobre pai

como Niobe, toda em lágrimas, por que ela, até mesmo ela,

Oh Deus, uma besta fera que não possui discurso de razão

Teria lamentado por mais tempo - casada com meu tio

O irmão de meu pai, mas tão parecido com ele

Quanto eu com Hércules. Dentro de um mês Antes que o sal das mais injustas lágrimas Tivesse deixado as marcas vermelhas em seus olhos injetados

Ela se casou. Oh, mais perversa pressa, precipitar-se com tal desembaraço em lençóis incestuosos Não, não pode ser, não pode vir para o Bem Mas explode coração, pois devo segurar minha língua

Neste desesperado monólogo, confrontam-se dois casais: de um lado, os pais de Hamlet, idealizados, e, do outro, Gertrude e o tio odiado. O príncipe compara o pai a Hipérion, deus solar de extrema beleza e a mãe, enquanto manteve-se a seu lado, a um ser frágil e dependente dele. A presença da solaridade de Hipérion, o mais alto ponto de mira do ideal, marca a superioridade da abóbada celeste, ao passo que Claudius e Gertrude remetem às partes baixas e ao registro telúrico, à incontrolável sexualidade de sátiros.

Ao lado deste deus solar a mãe surge como figura angelical, anterior à queda, cujo corpo era um "enclosed garden not yet grown to seed" - "jardim fechado, que ainda não começou a dar semente". São claras referências ao Jardim do Éden, à virgindade e à época que antecede a capacidade materna de procriar; esta será logo associada a uma horrível frutificação, degradante e pecaminosa. O corpo materno abre-se pelo incesto a um proliferar de germinações malignas, maldições de Pandora.

Há um estudo de Adelman, de 1992, que mostra a figuração do corpo materno, no imaginário de Hamlet, como um jardim que foi devassado em oposição ao estado

8. Niobe, uma mãe que chorava profusamente na morte de seus filhos.

9. Wants discourse of reason, que não tem o poder da razão.

10. Post, apressar-se.

11. Incestuous, a lei canônica considerava o casamento com o irmão do morto como incestuoso. 


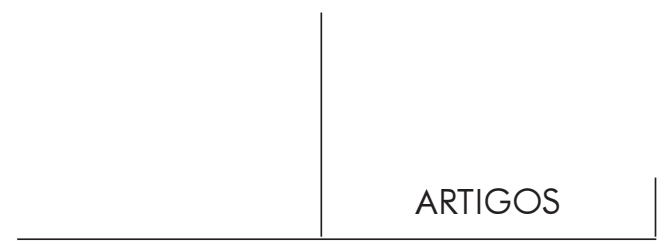

anterior, de jardim fechado; os opostos polarizam-se: pura e corrupta, virgem e puta, fechada e devassada. O texto deixa transparecer a fantasia de um nascimento virginal e a nostalgia da tríade pai-mãe-criança, como Sagrada Família. A concepção virginal por intermédio da graça realiza o desejo de um universo perfeito, não-corrompido pela relação sexual. Por outro lado, o leito nupcial dos sátiros, jardim devassado, gera, sem cessar, frutos sujeitos a apodrecer. As imagens transformam corpo e fecundação em algo que tende, constantemente, à degradação.

Tal atribuição de valor negativo ou "fecalização" do corpo faz parte do sistemático trabalho de depreciação do Eu e da atitude de desprezo com que pacientes deprimidos se referem ao próprio corpo. Muitos exemplos clínicos me ocorrem, como o de uma paciente, "Sofia", que sentia uma verdadeira repulsa em relação ao próprio corpo. Outro paciente, a quem dei o nome de Francisco, desenvolvera desde a infância um sentimento muito profundo de desprezo em relação a si, sentindo-se sempre "doentinho" e "fraquinho". Os remédios que era obrigado a tomar diariamente, para evitar as consequiências de uma doença infantil, adquiriram um caráter terrível, correspondiam a um veredicto, ao decreto irrevogável de sua condição inferior e doentia. Para estes pacientes, carregar o corpo era uma verdadeira via crucis.

No discurso exaltado de Hamlet sobre Gertrude e Old Hamlet aparece, no lugar do amor genital de um casal, um amor terno, um cuidar e proteger, mais típicos da descrição do que se passa entre a mãe devotada e seu filho. "He might not beteem the winds of heaven visit her face too roughly" - "Ele não deixava que a brisa do paraíso visitasse sua face de maneira muito rude". O trecho exprime uma profunda ternura ao focalizar a face, ao falar da brisa do paraíso, da necessidade do marido evitar que a frágil mulher fosse tocada por um vento mais forte: operações que não deixam de revelar certo trabalho de dessexualização. As palavras traem a idealização, a purificação e o caráter assexual deste amor maravilhoso, que se expressa sobretudo pelo gesto de cuidar, proteger e alimentar alguém. Podemos pensar que o desespero de Hamlet, antes da terrível descoberta do assassinato do pai, era um dolorido lamento pela quebra da unidade narcisista originária.

A lei canônica considerava incestuosa a união da mulher viúva com o irmão do falecido. Neste contexto, a genitalidade surge associada à idéia de queda e corrupção; não há lugar para uma sexualidade não-transgressora. O jardim, tradicionalmente imagem de integridade, como no caso do Jardim do Éden no centro do universo, torna-se espaço contaminado e a mãe virginal torna-se mãe abjeta.

Hamlet fica indignado com a fraqueza moral da mulher ("Fraqueza, teu nome é mulher"): pressente-se nesta queixa a ameaça que a sensualidade feminina representa para a virilidade e o mundo masculino. Ora, o desencadear da luxúria materna ocorre na vigência da ausência paterna, quando desaparece, assassinado em um jardim, a figura masculina idealizada que encarnava uma primeira ordem pré-genital. "Gertrude, como uma segunda Eva traz a morte para o mundo, transformando o jardim em um cemitério". (p. 3) 


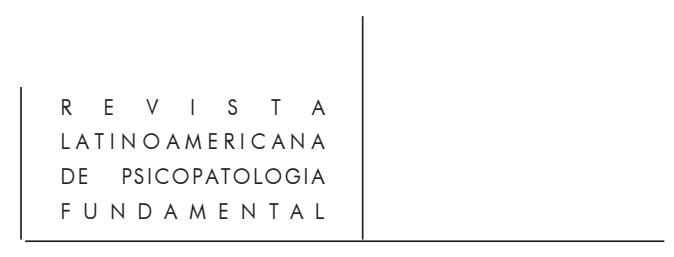

Os versos "O that this too too sullied flesh would melt, Thaw, and resolve itself into a dew", traduzidos por "Oh, e pensar que esta carne tão, tão manchada possa se derreter, se desmanchar e se dissolver em umidade", fazem uma clara referência à modificação dos órgãos genitais depois da resolução do orgasmo e também ao desmanchamento dos corpos depois da morte, estabelecendo uma associação mórbida entre sexo, pecado e morte. A sexualidade carnal é aviltante e a sensualidade mancha, dissolve a carne. Hamlet sente repugnância da carne, cujo tônus de excitação se desfaz no momento do orgasmo, mas que também se dissolve pelo processo da morte. É possível ouvir neste desprezo à inconsistência, à finitude da carne, a dor e a revolta do príncipe com a morte do pai e a dissolução de uma primeira ordenação do mundo, por ele encarnada. É o discurso indignado de quem não pode aceitar esta revogação. Ouvimo-lo exclamar sem cessar "Como pode ser isto verdade?", quanto à incontrolável luxúria materna, à morte do pai e o desaparecimento de uma primeira ordem narcisista.

Através da excitação sexual que dissolve, da morte e da inevitável corrupção do corpo, todo o universo é ressignificado como degradante - "Há algo de podre no reino da Dinamarca". Ao mesmo tempo, o amolecimento da carne e a presença da umidade remetem à relação sexual em um contexto extremamente mórbido. Além da degradação do corpo por meio da morte e do sexo, há um lamento muito doloroso em relação à degradação e ao amolecimento do caráter. $\mathrm{O}$ amolecimento se refere à perda de retidão, força, coragem e honestidade, referentes ao tio e à mãe, mas também a si próprio. Jones mostra que Hamlet passou a ter contato com suas fantasias incestuosas e parricidas que o tornaram especialmente indigno aos próprios olhos, como se o princípio de podridão contra o qual lança seu grito estivesse instalado no centro de si mesmo.

"Fie on't, ah fie, 'tis an unweeded garden. That grows to seed. Things rank and gross in nature. Possess it merely. That it should come to this:" traduzido por "Vergonha, ó vergonha; (ela) é um jardim de onde não foram retiradas as ervas daninhas. Que cresce para uma horrenda frutificação. Tudo se torna indecente e aviltante na natureza. Até possuí-la por inteiro. ... Que tenha podido ter chegado a isto!"

Este jardim de onde não foram retiradas as ervas daninhas é tanto a mãe quanto ele próprio, em sua transgressora carnalidade. No caso da mãe a imagem se endereça ao ventre materno, onde crescem ervas daninhas, frutos "malditos" em contraponto com o "bendito" fruto virginal. Toda esta mulher, Gertrude, tornou-se abjeta: corpo, ventre, caráter, ações; a horrível frutificação multiplica-se, espalha a degradação, "até possuí-la por inteiro". Sobretudo o ventre materno torna-se local abjeto pois simboliza a possibilidade de multiplicação da carne abjeta. Há nisto uma referência direta a si mesmo, Hamlet, fruto "daquela" mulher, e portanto herdeiro de sua abjeção.

Ao mesmo tempo o local dos frutos é o pomar onde foi assassinado seu pai e também, no relato bíblico, lugar da queda onde nudez, culpa, genitalidade, morte e 


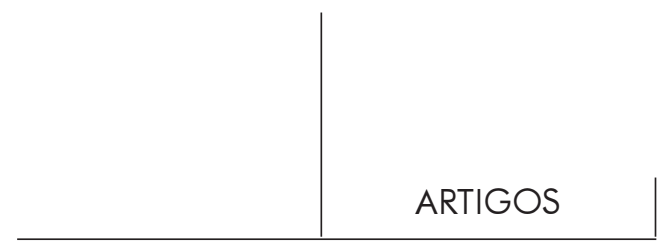

mentira se entrelaçam Os veementes protestos de Hamlet permitem supor, além da indignação com a morte do pai e a indesculpável traição da mãe, o sentimento amargo de ter sido, ele próprio, traído pela mãe. Todo este monólogo faz lembrar, dramatizando-o, um sentimento de profunda decepção que vivem as crianças quando, acreditando ter a mãe exclusivamente para si, descobrem, de repente, que a relação idílica dos primeiros anos é agora atravessada por excitações e rivalidades antes inexistentes e que o corpo materno é o palco de acontecimentos até então insuspeitados. É a lamentação que costuma acontecer quando a criança descobre que os bem-aventurados tempos de relação paradisíaca com a mãe começam a sofrer a interferência de rivais; além do pai, a descoberta da própria genitalidade com suas obscuras fantasias violentas e a descoberta de que a mãe é também um ser sexuado. Tudo isto cria um acréscimo atormentado de excitações obrigando ao mergulho de tudo na amnésia infantil. Normalmente a criança se sente movida a responsabilizar o pai pelo estrago ocorrido em sua concepção ideal de amor. No caso de Hamlet, o provocador de todo o estrago é o tio, mas a mãe também é vista como traidora, como pertencente a este insuportável mundo sexuado, ao qual não quer pertencer. ("Quão cansativos, velhos, superficiais e não proveitosos me parecem todos os objetivos deste mundo").

A tragédia de Hamlet trabalha muito bem o contraste entre luz e sombra e talvez esta imagem possa nos ser útil para pensar a questão dos ideais e a má resolução do Édipo na melancolia. A cena que dá início à peça ocorre por volta da meia-noite; é uma conversa entre os vigias-noturnos, ameaçados pelo terrível fantasma do velho rei morto. Contra a densa sombra da noite, o impacto súbito e fulgurante da aparição paterna é uma luz insuportável; produz mais escuridão (“... a sombra do objeto cai sobre o Eu...”). Hamlet compara o pai ao deus solar Hipérion fazendo pois alusão a esta luminosidade esmagadora. Ao longo de todo o primeiro solilóquio ouve-se o apaixonado movimento de idealização do pai da primeira infância, a nostalgia do clima idílico de amor livre de ciúme, rivalidade, culpa, vergonha. A presença de um rei poderoso e solar ao lado de uma mulher frágil, infantil, levou-nos a transformar a descrição de tão puros amores, na cena amorosa entre mãe e filho, momento em que a presença paterna não produz ainda rivalidade, mas compõe o romântico quadro de uma família sagrada, da qual foram subtraídas todas as emoções negativas e as contradições humanas. Acho que esta imagem luminosa e perfeita é um retrato da vivência narcisista primitiva em seu aspecto amoroso, claro, tranqüilo e eternamente igual a si própria, uma vez que nada poderia perturbar tal harmonia.

Se acrescentássemos a este quadro um tanto estático a idéia de variação entre luz e sombra, a luz correspondendo a todos os momentos de plenitude narcisista, e a sombra às inevitáveis frustrações e desencontros, teríamos de admitir que todo processo de desenvolvimento transcorre em uma atmosfera cambiante de luz e sombra. Além disto é possível supor que a melhor condição para a manutenção da 


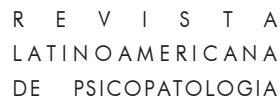

vida encontra-se na faixa intermediária entre o excessivo brilho da luz e a completa obscuridade.

Entretanto, na aparição do pai morto e no desespero de Hamlet há uma luz absoluta, incapaz de compor-se com a sombra aconchegante de uma clareira, que em vez de iluminar cria uma superexposição que precipita tudo na mais densa treva. É possível supor a gênese melancólica de Hamlet como um acontecimento anterior à morte do pai e o casamento da mãe. A experiência de plenitude narcísica dos primeiros tempos, absoluta e luminosa não pôde entretecer-se com a estranha realidade de excitações genitais, portadoras da diferença dos sexos, rivalidade, descoberta dos pais sexuados, culpa e vergonha. "Muito poucos separam-se dos pais", já dizia Freud, e entrar no mundo da sexualidade é tão denso que a nostalgia do narcisismo primário torna-se forte. Tornar-se melancólico é não poder integrar em si nem os pais sexuados nem as próprias excitações genitais com sua violenta passionalidade. A integração da condição humana sexuada é bloqueada por mensagens superegóicas carregadas de culpa e condenação. As excitações genitais crescentes que bombardeiam a criança desde os três anos de idade, impedidas de passar por um processo de simbolização, vão alimentar esta exaltação exagerada do amor terno e prégenital, criando a fantasia de um tempo originário de amor legítimo e puro.

A fantasia da unidade narcisista perfeita adquire o status de uma realidade muito especial, exercendo uma dupla recusa: por um lado, da realidade do Eu corporal e suas excitações e, por outro, dos caminhos identificatórios oferecidos para a realização da sexualidade genital. É verdade que no caso de Hamlet a genitalidade transgressora e manchada de sangue da mãe tornava o caminho escolhido por Gertrude algo abominável para Hamlet, e "quão cansativos, velhos, superficiais e não proveitosos me parecem todos os objetivos deste mundo".

Se a mãe é pura treva e o pai é pura luz, não há formação de compromisso possível. No solilóquio desesperado, a luz fulgurante de Hipérion cai sobre Hamlet ao mesmo tempo que a sombra materna o esmaga. $\mathrm{O}$ brilho absoluto de um objeto hiperidealizado, e por isto mesmo considerado inalcançável e irrecuperável, é o que faz emergir, como se fosse a outra face da mesma realidade, a sombra temível do objeto que ameaça esmagar o Eu, no caso da melancolia. Por outro lado, o que leva a bom termo o desenvolvimento afetivo é um longo processo de integrações, separações e combinações entre sombra e brilho dos objetos de amor, entre o interdito do incesto e as identificações simbólicas que dão acesso a um destino sexuado. A patologia aqui pode ser atribuída a um excesso de luz, que não se compõe com a sombra e que mantém dissociados os dois pólos extremos, funcionando em um regime de tudo ou nada.

O luto normal dos pais ideais envolve sempre um longo processo de integrações, separações e recombinações entre luz e sombra. O que se passa na melancolia, que é uma recusa a entrar no processo do luto, poderia ser descrito como uma fixação 


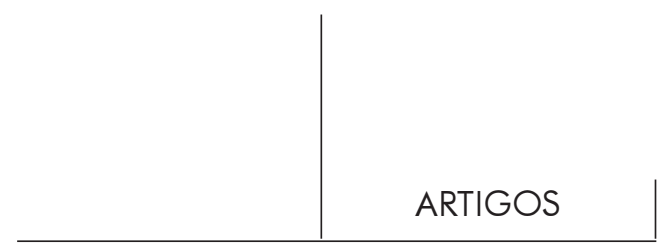

inconsciente à luz, que por ser vívida demais, não pode nunca compor-se com a sombra. Uma vez dissociados os dois extremos, a vida torna-se impossível, o desejo de morrer fica intenso, a tendência ao suicídio torna-se forte, não há lugar para existir. Hamlet, ele próprio, lamenta a lei contrária à destruição de si, pois tudo que deseja é evadir-se deste mundo que não oferece nenhuma esperança de realização de ideais.

Diante da impossibilidade de recuperar o brilho bem-amado de seus objetos infantis, é muito difícil continuar a viver em um mundo onde tudo parece destinado a corromper-se. O mundo interno foi despedaçado e fecalizado; a impossibilidade de compatibilizar luz e sombra torna-se ainda mais aguda quando Hamlet descobre o assassinato do pai pelo marido da mãe. Se, em fantasia, havia desejado matar o pai e possuir a mãe, a realização factual dos crimes era excessivamente crua e aviltante; tornava-se impossível partilhar desta condição carnal, permanecer na carne.

A imagem do brilho e da sombra introduz a questão da clivagem e da possibilidade de diminuir a amplitude desta separação entre pólos extremos, funcionando em regime de tudo ou nada. Em toda estruturação psíquica há sempre presença de algum tipo de clivagem do Eu, embora a patologia esteja associada a uma clivagem de maior amplitude e imobilidade, isto é, que não entra em um movimento dialético de integração e discriminação. A clivagem máxima entre o brilho ideal do objeto parental, o Hipérion celeste e a condição abjeta e fecal do próprio corpo, pura sombra, é isto que torna a vida inviável para o melancólico. É perdida a esperança de que um dia este Eu precário poderá se encontrar com o Ideal e novamente experimentar um estado de fusão nesta existência terrestre e, na ausência disto, sobra o desespero, o sentimento de nulidade. Fica impossível projetar alguma coisa para o futuro, e sente-se que o Eu está amortalhado por um manto de trevas, pois a brecha existente entre Eu e Ideal jamais poderá ser fechada.

A única esperança para o melancólico é o suicídio, pois através da morte há a esperança, digamos assim desesperada, de encontrar-se com o Ideal, há esperança de resgate e salvação por meio do ato de se despojar da própria vida, pagando o maior preço pelo maior bem. Matar o Eu abjeto e eliminar todos os traços da sujeira e da impotência deste Eu fecalizado conduz à fantasia megalomaníaca de deixar que persevere somente o Eu Ideal, o Hipérion solar, que liberto enfim desta mortalha carnal, poderá durar para sempre no seu círculo solar. A megalomania associada ao ideal fálico é a contrapartida da micromania, que faz com que o Eu corporal se torne o pior, o mais abjeto e pútrido representante deste mundo. Mesmo na micromania do melancólico pode-se ler, pelo uso do superlativo "o pior, o último, o mais abjeto", a mesma dinâmica da megalomania, com o sinal invertido.

A situação que Hamlet lamenta ter perdido parece uma posição anterior ao Édipo, na qual filho e pais formavam uma tríade narcisista, evitando desta forma o aparecimento de situações de conflito. É uma posição extremamente gratificante e sua perda provoca o surgimento de uma agressividade intensa. A criança se recorda desta 


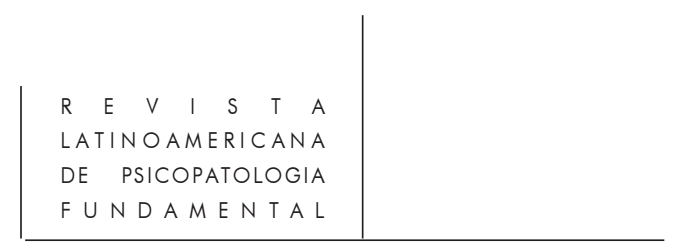

época como de um tempo de supervalorização narcisista, uma espécie de apogeu. Grunberger (1993) afirma desta posição: "Compreende-se que esta posição euforizante possa ser buscada, verdadeiro porto de graça e quietude, abrigo certo contra algumas situações particularmente angustiantes. Nesta posição o sujeito se encontra em oposição ao Édipo. Não se trata de amar um dos pais e detestar o outro, mas de ser amado pelos dois pais simultaneamente, de um modo narcisista, absoluto, fusional e a-conflitual" (p. 203).

O texto literário de Shakespeare leva-me a cogitar que este primeiro narcisismo é de certa forma a tendência a um amor que conduz à morte, assim como no mito de Narciso, transparece o medo de se relacionar, a opção por uma forma impossível de amor que necessariamente leva à "des-encarnação". A busca de ser amado é diferente da busca de amar um outro. Se por um lado a tendência narcisista expressase pelo desejo de ser amado, por outro, a presença de um ideal fálico como Hipérion, o deus solar, mostra que há também busca de divinização, neste desejo de atingir a plenitude da perfeição.

Esta forma de narcisismo absoluto é simultaneamente desejo de divinização e um poderoso princípio de negação da carne, um "convite" a desencarnar. É, ainda, um veemente repúdio contra a inconsistência, finitude e o tônus transitório da carne, o que pode ser re-encontrado, com características um pouco diferentes na bela indiferença das histéricas que depreciam o ato sexual em nome de um apaixonamento "trovadoresco". ${ }^{12}$ Convém ressaltar que a "bela indiferença" na histeria é menos radical do que na melancolia: são diferentes maneiras de livrar-se do peso e do trabalho exigidos para apropriar-se do corpo.

Esta forma absoluta de narcisismo revela a impossibilidade e a recusa de sustentar e assumir a própria vida pulsional: é um princípio de desencarnação que pode ser atribuído ao trabalho da pulsão de morte. Do outro lado, a aceitação do desamparo, da falta e do desejo é o princípio oposto, de encarnação, de humanização e de entrada na elaboração das exigências de trabalho que a vida pulsional faz ao aparelho psíquico.

\section{Referências}

Adelman, Janet. Suffocating Mothers: Fanasies of Maternal Origin in Shakeaspeare's plays, Hamlet to the Tempest. London and New York: Routledge, 1992.

Bollas, Christopher. Hysteria. São Paulo: Escuta, 2000.

CAlvino, Ítalo. O cavaleiro inexistente. Lisboa: Editorial Teorema, 1986.

Freud, Sigmund. Obras completas. Buenos Aires: Amorrortu, 1982. v. I.

12. O livro de Ítalo Calvino O cavaleiro inexistente descreve de modo hilariante a superioridade infinita de um amante sem corpo sobre um outro, vulgarmente encarnado. 


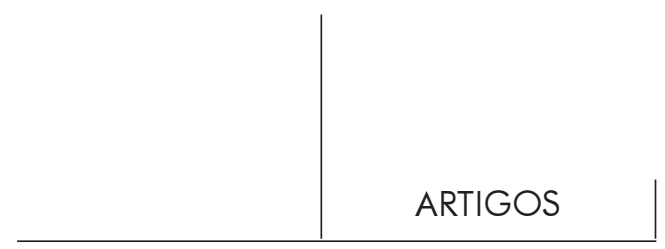

Grunberger, B. Le narcisisme: essais de psychanalyse Paris: Payot, 1993.

Jones, Ernest. Hamlet \& Oedipus. New York: Doubleday, 1954.

KRISTEVA, Julia. Sol negro - Depressão e melancolia. Rio de Janeiro: Rocco, 1989.

LacAn, Jacques. Hamlet, por Lacan. In Shakeaspeare, Duras, Wedekind, Joyce. Lisboa: Assírio \& Alvim, 1989.

SHAKeSPEARE, William. Hamlet. Edited by Edward Hubler. The Signet Classic Shakeaspeare General Editor: Sylvan Barnet. New York: Penguin Books, 1987.

\section{Resumos}

El texto presenta un análisis del primer monólogo de Hamlet, de Shakespeare como ilustración poética del proceso más primitivo de construcción de ideales desde un punto de vista psicoanalítico. Del lado del ideal de máxima perfección (yo ideal) estan el padre de Hamlet y la situación familiar primordial (Old Hamlet, Gertrude e Hamlet) formando una tríada narcisista primaria.

Del lado contrario (yo abyecto) el texto explora el mayor grado de infamia a que un ser humano puede llegar, en este caso, el casamiento de Gertude (madre de Hamlet) com Claudius después de la muerte del viejo Hamlet.

La oscilación sobre el eje de los valores entre posiciones tan extremas es indicadora de la falta de transformación del narcisismo primario y de la imposibilidad de construir ideales secundarios (ideales del yo).

Palabras claves: Hamlet, psicoanálisis, melancolía, yo ideal

Le texte présente une analyse du premier soliloque de Hamlet, de Shakeaspeare, comme illustration poétique des processus les plus anciens de construction des idéaux, selon la psychanalyse.

Du coté de l'idéal de la plus haute perfection (Moi Idéal) sont le père de Hamlet et la situation primordiale de la famille, c'est à dire, mère, père et enfant ensemble dans une triade narcissique primaire.

A l'oppose, Hamlet parle de sa mère aprés le mariage avec Claudius comme de quelqu'un qui est tombé dans l'état d'abjection le plus bas possible pour un être humain.

L'oscillation entre ces deux positions extrêmes démontre qu'il n'y a pas eu transformation du narcissisme primaire et construction d'idéaux secondaires.

Mots clés: Hamlet, psychanalyse, mélancholie, moi idéal

This text analyses Hamlet's first soliloquy in Shakespeare's play of the same name, using it as a poetical illustration of the earliest process of construction of ideals, seen from a psychoanalytic point of view.

On the one hand, there are there are two figures that are highly idealized as Ego Ideals: Hamlet's father and the primitive family situation involving father, mother and child joined together in a primary narcissistic triad. 


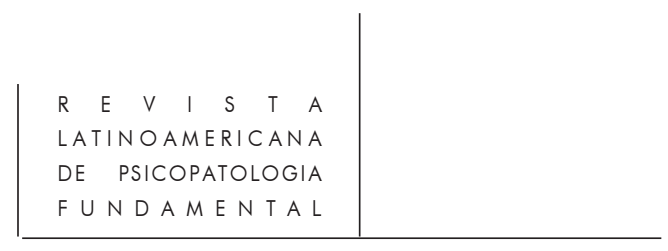

On the other hand (the abject Ego), when describing his mother at the moment she marries Claudius, Hamlet shows the lowest point of abjection that a human being can fall to.

The oscillation between these extreme positions of positive and negative values shows that primary narcissism has not been transformed to allow the construction of secondary ideals (Ego ideals).

Key words: Hamlet, psychoanalysis, melancholia, ego ideal

Versão inicial recebida em fevereiro de 2001

Versão aprovada em novembro de 2001 